\title{
ТЕХНИКО-ТЕХНОЛОГИЧЕСКИЕ
} ИННОВАЦИИ

DOI: http://dx.doi.org/10.15688/jvolsu10.2014.4.3

УДК 541.121:621.391

ББК 35.71

\section{RECENT ADVANCES ON MONTMORILLONITE-BASED FIRE RETARDANT COMPOSITES IN POLYMER MATRICES}

\section{Cai Guipeng}

Doctor of Sciences, Professor,

Department of Chemistry and Fire Retardants, Research Center of Marquette University

charles.wilkie@marquette.edu

Wisconsin Avenue, 1250, Milwaukee, WI 53233, USA

\section{Wilkie Charles A.}

Doctor of Sciences, Professor,

Department of Chemistry and Fire Retardants,

Research Center of Marquette University

charles.wilkie@marquette.edu

Wisconsin Avenue, 1250, Milwaukee, WI 53233, USA

\begin{abstract}
Fire retardancy in the future will likely involve a combination of materials that all function as fire retardants but each offers something different. In this paper, it is suggested that a nano-dimensional material, possibly and organically-modified montmorillonite, will be one of the components. Drawing examples from a number of different systems, this is elucidated in this paper.

Key words: fire retardancy, montmorillonite, nanocomposites, polymer matrix, environmental concerns.
\end{abstract}

\section{Introduction}

Fire retardancy of polymeric composites has been extensively studied in the past decade and the halogen-based fire retardants, which have been the workhorse of the industry for many years, have been more and more questioned due to environmental concerns. Recent studies on human exposure to flame retardant chemicals reveal that the bromine-containing fire retardants (FRs) can degrade to form carcinogenic brominated dioxins and can even be absorbed by the human body [14; 
23]. Thus, the need for green FRs which can replace the halogens is more and more necessary. While there are a large number of potential fire retardant, this review focuses on montmorillonite (MMT) and its combination with other materials. Since the fire retardancy due to MMT was first discovered in polymer matrices by Gilman et al [21], this type of green, low-loading effective (usually 3-5 wt \%) material has been of continued interest globally. A substantially reduced peak heat release rate (PHRR) is the principal interesting feature of MMT-based polymer composites. Two major factors which may be considered detrimental are the shortened time to ignition (TTI) and the almost unchanged total heat release (THR) [32]. In addition, MMT alone in polymers does not improve the classification in the UL94 protocol. Thus, if MMT is to be useful, it must be used in combination with other fire retardants. We believe that combinations of fire retardants is, in general, the wave of the future, and, in principal, we think that MMT can be useful as one of the materials to be combined. In this review, combinations of clay (montmorillonite) with other fire retardants are examined.

First of all, the processes by which MMT enhances fire retardancy will be reviewed. This will be followed by a section on the effects of dispersion, then combinations with intumescent fire retardants, then with other fillers and finally the layer-by-layer technique to achieve good fire retardancy will be addressed.

\section{Processes by which fire retardancy is achieved using MMT}

There are two processes by which fire retardancy is achieved using MMT, the formation of a barrier, which reduces transport of material from the polymeric phase to the vapor phase and also reduces the ability of heat to transfer to the underlying polymer, and paramagnetic radical trapping, which traps degrading polymeric radicals so they cannot enter the vapor phase. Barrier formation was first proposed by Gilman [21] who suggested that the rising bubbles during burning may carry the clay to the surface where it acts as a barrier. This has been further studied in a series of papers from this laboratory in which it was shown that the reduction in the peak heat release rate is related to the stability of the radicals that are formed. When very stable radicals are produced, the reduction in the PHRR is low while for more unstable radicals, the reduction can be larger $[26 ; 27 ; 43 ; 58]$. The notion that the material actually rises to the surface as opposed to simply acting as in in situ barrier was addressed in a later paper [13].

Paramagnetic radical trapping was first suggested in 2001 [59]. It was found that a significantly reduced PHRR was obtained when the amount of clay was clearly insufficient to produce the necessary barrier. By comparing ironcontaining clays with those in which iron was absent, the necessity of the iron was shown. This has recently been experimentally shown to be true by Carvalho et al [12].

\section{Dispersion of MMT in polymer matrix}

In most cases, the dispersion of an organically-modified MMT is the most important factor in the fire performance - if the MMT is poorly-dispersed, the fire performance will be poor while if there is good dispersion, whether intercalated or exfoliated, there will be a substantial reduction in the PHRR [52]. Thus, the dispersion of organo-MMT in polymer matrices and the adaptation of new surfactants to enhance the dispersion of organoclay in polymer matrices is also described herein.

During the past two decades, the investigation of polymer/MMT composites reveals that dispersion of MMT plays an important role in the physical, mechanical and flammability properties $[4 ; 19 ; 42]$. Polymers are generally covalent compounds and show weak or no polarity but pristine montmorillonite is an ionic compound and exhibits relatively strong polarity. Therefore, the compatibility between the polymer and clay must be enhanced and this is done using long chain surfactants. Surfactants play the role of an amphiphile, having two functional moieties, a polar end and a non-polar end, which enhance the compatibility between polymers and clays. There are some problems with the conventional quaternary ammonium surfactants, primarily their low thermal stability. However, phosphonium surfactants are more thermally stable compared to the ammonium salts and can be used [58]. Pack et al. employed resorcinol diphenylphosphate (RDP) oligomers as a surfactant to modify pristine 
MMT [43]. RDP is a phosphorus-based fire retardant with good thermal stability, high efficiency, and low volatility [37]. If RDP can be intercalated into MMT, it can play a dual role both as a surfactant and as a fire retardant. First of all, one part (by weight) RDP was melted in a beaker with continuous stirring, then four parts of pristine MMT clay was added with stirring until the liquid was completely adsorbed into the clay powder. The modified clay was then placed in a vacuum oven at $100{ }^{\circ} \mathrm{C}$ for $24 \mathrm{~h}$ to remove moisture and unabsorbed liquid. Small-angle X-ray scattering (SAXS) and atomic force microscope (AFM) results supported the intercalation of RDP into MMT galleries. This method does not need solvent, so it is a green method to produce modified MMT. The RDP-MMT was incorporated into various polymers, including high-impact polystyrene (HIPS), poly(methyl methacrylate) (PMMA), acrylonitrile butadiene styrene (ABS) and polypropylene (PP), and binary polymer blends, like PS/PMMA and polycarbonate (PC)/ poly (styrene-co-acrylonitrile) (SAN24). They also used Cloisite 20A to blend with the above polymers as a reference. RDP-MMT is more compatible with the styrene groups compared to the Cloisite clays, which could lead to exfoliation in HIPS and ABS. Although they did not use cone calorimetry, the gasification evaluation revealed that PC/SAN24/RDP-MMT exhibits a more remarkable PHRR and MLR reduction than the polymer blend with Cloisite 20A. In a similar study, Lai et al. also adopted RDP-modified MMT in a PP/IFR system. They did not employ the direct melt blending method to intercalate RDP into MMT, rather they used solvent mixing in ethanol. The d-spacing of modified MMT is $2.15 \mathrm{~nm}$, which is close to that of the melt blended system $(2.23 \mathrm{~nm})$. Due to the high thermal stability of RDP, the onset decomposition temperature and the maximum decomposition rate temperature of $\mathrm{PP} / \mathrm{IFR} / \mathrm{RDP}-\mathrm{MMT}$ are higher than PP composites with conventional quaternary ammonium salt modified MMT (O-MMT). The amount of MMT is varied between 0 and $6 \%$ and PP/IFR/RDP-MMT shows a slightly increased LOI value compared to PP/IFR/OMMT (less than or close to $1 \%$ increase) and the UL94 ratings of those two systems are also the same; in other words there is no improvement by these methods of evaluation. The cone results of PP/IFR/RDP-MMT show a more reduced PHRR value compared to the system without RDP, PP/IFR/O-MMT, and thicker chars are obtained after burning compared with the composites with or without O-MMT.

If the surfactant used to modify pristine MMT can also intumesce, this might make a nice method to prepare fire retardant materials. Huang et al. synthesized a phosphorus-nitrogen containing compound, 2-(2-(5, 5-dimethyl-1, 3, 2-dioxaphosphinyl2-ylamino) ethyl-amino)-N, N, N-triethyl-2oxoethanaminium chloride, which was denoted as compound. It takes three steps for the synthesis and the final yield is about $30 \%$. They used this compound to modify pristine MMT and combined it with polyurethane to form composites. No discernible XRD peaks of the composites indicated that a disordered structure was obtained, although they claimed exfoliation instead. The TEM images reported in this paper to our eyes do not suggest exfoliation. A major problem occurs when nanodispersion is asserted based only on the absence of a peak in the XRD or poor quality TEM images. The PHRR reduction from the cone calorimetry is moderate ( $25 \%$ ) even at $20 \% \mathrm{c}$-MMT loading, which also indicates a disordered structure rather than an exfoliated structure. The two advantages of this system are the prolonged time to ignition (TTI) and reduction of smoke. Later, they synthesized another phosphorus-nitrogen containing compound, 2, 4, 8, 10-Tetraoxa-3, 9-diphosphaspiro [5.5]-undecane-3, 9-dioxide-disubstitutioacetamide-N, N-dimethyl-N-hexadecyl-ammonium bromide (PDHAB), which they combined with LDPE/EVA [25]. The synthesis is also a threestep process, but the final yield is higher than previous one, around $40 \%$. Moreover, supported by XRD and TEM, this two-long-tail surfactant seems to enhance the compatibility between LDPE/EVA and MMT. The two advantages of previous system in cone calorimetry remain in this system. The PHRR reduction in this system is still moderate $(28 \%)$. Despite the nice idea of combination of surfactant and intumescent effect, the complicated synthetic process and relatively low yield may limit practical applications of the above systems.

In another study, a twice modified organoclay, which they call a dual modified clay (DMC), was prepared by successive cationic exchange reactions of pristine MMT with two 
intercalating reagents, hexadecyltriphenylphosphonium bromide and 2-methacryloxy-ethylhexadecyl-dimethyl-ammonium bromide. This method increases the d-spacing of organomodified MMT from $1.20 \mathrm{~nm}$ of pristine MMT to $2.49 \mathrm{~nm}$. The XRD patterns and TEM images supported an exfoliated structure of PMMA/ DMC-3\% nanocomposites. Mechanical properties, such as the tensile strength, elongation at break, break stress, and modulus, increase considerably compared with control PMMA. The only fire test conducted in this paper was LOI. All samples' LOI (DMC at $1 \%, 3 \%$ and $5 \%$ ) values are lower or equal to 21 , which means they have had no effect on the ease of extinguishment, which is what is evaluated by LOI. The PMMA/DMC nanocomposites are prepared through a casting method which needs a highly dilute solution in $\mathrm{N}$-methyl-2-pyrrolidone (NMP) as a solvent. Thus, this method is not appropriate for large scale production and the process may not be green.

Based on a previous study, which suggested that ultrasonic treatment enhances the intercalation of clay in HDPE, increasing the d-spacing up to $50 \%$, Swain et al. further investigated PMMA/clay nanocomposites synthesized by an ultrasonic-assisted emulsifierfree emulsion polymerization technique. In order to enhance the dispersion of the clay layers in the polymeric matrix, ultrasonic waves of different power and frequencies were used. XRD and TEM results indicated enhanced dispersion of MMT after ultrasonication. Among the mechanical properties, toughness increased significantly compared with the composites without ultrasound. LOI was the only fire evaluation in this work and it was insignificantly improved by ultrasound in PMMA/clay composites. PMMA is very difficult to fire retard so this may not be a good material to use to evaluate novel systems.

\section{Combination of organoclay and intumescent fire retardants (IFRs)}

On one hand, intumescent flame retardants (IFRs) have been widely studied due to their advantages, such as low smoke, low release of toxic gases and anti-dripping, etc.; on the other hand, there are also disadvantages, including cost-ineffectiveness, low thermal stability and the weakness of the char structure. The barrier effect of nano-clay may help improve the char strength and fire retardant efficiency as well. Ribeiro et al. investigated the synergy between various commercial MMTs and a standard intumescent formulation containing ammonium polyphosphate (APP) and pentaerythritol (PER), in the matrix of a poly [ethylene (30\%)-butyl acrylate] copolymer. They found a relation between the d-spacing of MMTs and fire retardancy performance. For the five commercial organo-MMTs (Cloisite 10A, 15A, 20A, 93A, 30B), the LOIs were all the same when only the clay was added, indicating that clay alone does not have an effect. On the other hand, when both clay and the intumescent system were present, the LOIs increased from 20 to almost 30 . This is an increase but it is very doubtful if that will have any effect on the fire retardancy. They also selected the lowest dspacing clay (30B) and highest d-spacing clay $(15 \mathrm{~A})$ in the same polymer matrix and conducted the UL94 evaluation. The results show that the former obtains a V0 rating while the latter obtains only a V2 rating; however, the polymer/ Cloisite $\mathrm{Na}^{+}$also obtains a V0 rating, which indicates that it is the intumescent, and not the clay, that dominates.

In a paper from the group of Wang et al., IFR composites based on ethylene-propylenediene terpolymer (EPDM) with organo-MMT and organo-modified MgAl-LDH were studied. The IFR was composed of APP and a nitrogencontaining carbonization agent $(\mathrm{CA})$ poly $(1,3$, 5-triazin-2-aminoethanol diethylenetriamine), in a 3:1 ratio (by weight). They keep the total loading of filler(s) at $32 \mathrm{wt} \%$ and the respective fillers (IFR, organo-MMT or LDH) vary. The combination of high IFR loading $(30 \%)$ and loading of organo-MMT or LDH ( $2 \%)$ is more effective in fire performance than the combination of low loading of IFR $(27 \%)$ and high loading of organo-MMT or LDH (5\%). The same amount of organo-MMT is more effective in PHRR reduction $(54 \%$ and $69 \%$, respectively) than that of $\mathrm{LDH}(51 \%$ and $60 \%$, respectively). This result is consistent with previous research from the Wilkie group, which also compared MMT and MgAl-LDH in PMMA matrix, but without IFR. 


\section{Combination with other fillers (CNT, ZrP etc.)}

The combination of MMT and other fillers may result in enhanced fire retardancy properties, however, some questions still need to be addressed. Is there always synergy between MMT and other FR fillers? How important is compatibility; is there an optimum ratio? The combination of MMT and metal hydroxides are studied initially by Beyer et al. in EVA matrix in order to reduce the high loading of metal hydroxides, normally $60 \mathrm{wt} \%$ or higher [7]. Instead of alumina trihydrate (ATH), Lenza et al. did a thorough investigation of magnesium hydroxide $(\mathrm{MH})$ in the high density polyethylene (HDPE) matrix in combination with MMT [36]. The MMT loading is in a range of $1-5 \mathrm{wt} \%$ and MH 10-55 wt \%. In this study, the MH-containing composites show an increased TTI compared to control HDPE. MH at $45 \mathrm{wt} \%$ loading in HDPE resulted in remarkable reduction in PHRR (86\%); the addition of $5 \mathrm{wt} \%$ MMT did not produce a substantial increase in PHRR reduction (88\%). The LOI value increases from 25.6 (HDPE/ MH $45 \%$ ) to 28.3 (HDPE/MH $45 \%$ / EVA/ MMT $5 \%$ ), which is the same value obtained in HDPE/MH $50 \%$. In another study, in order to enhance the compatibility of hydrophilic $\mathrm{MH}$ with hydrophobic polymers, the incorporation of $\mathrm{MH}$, with and without silanization, was investigated by Suihkonen et al. in epoxy-based composites [53]. The silanized MH shows better compatibility with epoxy matrix by scanning electron microscope (SEM) observation. However, when the fire performance was evaluated by cone calorimetry neither nano-scale nor microscale $\mathrm{MH}$, whether silanized or not, exhibited a discernible difference. This is probably due to the mechanism of $\mathrm{MH}$ during the burning process, which decomposes and produces water vapor to absorb the heat of combustion and nano-dispersion is not necessary. This result also reminds us that, although the term "nano" has been an oft used concept, it is not necessary that every material be a nano-material. Different situation may need different consideration.

Carbon nanotubes (CNT) have found various applications due to their desirable mechanical and thermal properties. Since there are innumerable papers addressing CNT's many properties, here the focus is only on the fire retardancy behavior, especially in combination with MMT. Beyer and Kashiwagi did some pioneering work in this area $[7 ; 31]$. They found that CNT shows superior or equivalent efficiency in FR relative to that with same amount of MMT. Despite the reductions in HRR/MLR of polymer/ CNT nanocomposites (using a conventional cone calorimeter), in most cases, the polymer was completely burnt leaving behind only a layer of CNTs. So, it is believed that CNTs may be addressed as an adjuvant in certain systems and scenarios rather than as a general fire retardant. Moreover, due to relatively high cost of CNT, combination of CNT with cheaper MMT may result in better fire performance and be more cost effective. Cai et al. investigated the combination of multi-wall carbon nanotubes (MWCNT) and organoclay modified with two-chain benzimidazolium surfactants with melamine as an additional FR in polyamide 6 (PA6) [9]. The higher steric hindrance in the presence of benzimidazolium modified silicate layers resulted in poor dispersion in a PA 6 matrix. Furthermore, this had a negative effect on the dispersion of CNTs in the ternary nanocomposite. The additional presence of melamine also had a negative effect on the thermal stability of CNT reinforced composites. Also due to poor dispersion of organoclay, no positive interaction between organoclay and CNT in FR performance was observed. This must remind the reader that simply combining two or more materials does not lead to a synergistic combination. Synergy is a badly misused term in the field of fire retardancy and it must be mathematically proven in each instance.

The combination of MMT and other materials, such as a Lewis acid type transition metal has been investigated in the past decade [7;26]. The purpose of this combination is to enhance formation of more homogeneous char without or with fewer cracks. Recently, Kashiwagi et al. studied MMT-based poly (acrylonitrile-co-styrene) (SAN) nanocomposites with zinc chloride as a catalyst system, which were prepared by the solvent casting method to explore possible synergistic flame retardant effects. The presence of zinc chloride did increase the amount of char of the composites, but with larger cracks as well. They explained that the char formation of zinc chloridecontaining composites occurs in the later stage of 
the gasification process, while, SAN-clay nanocomposites form small cracks in the surface layer at the early stage. Thus, each additive acts independently, without any synergy. At the end of their work, they suggested that catalysts forming char at earlier times are needed to obtain such synergy. In subsequent work from the same group, a series of phosphomolybdates (PMo) with different cations, including ammonium phosphomolybdate hydrate (NHPMo), melamine phosphomolybdate hydrate (MEPMo), zinc phosphomolybdate hydrate (ZnPMo) and sodium phosphomolybdate hydrate (NaPMo), were used as catalysts, combined with MMT clay, to flame retard SAN. Among the four PMo salts, some synergistic effects were seen in the combination of NHPMo with Cloisite 20A which is probably due to the overlapping degradation temperature range of the combination of $20 \mathrm{~A} /$ NHPMo and SAN40, which probably enhances char formation. This result flows directly from suggestions raised in the previous paper. Another possible reason is that more NHPMo may be around or on the clay stacks and less in the gallery space, which probably bridges the clay stacks with char formed around clay and forms a stronger network during the degradation process. The other three PMo salts also form network structures, but they break down at higher temperatures.

In another study, nano-dispersed cerium (IV) dioxide $\left(\mathrm{CeO}_{2}\right)$ has been found to exhibit significant FR enhancement at low loadings $(2.3 \mathrm{wt} \%$ or $4.6 \mathrm{wt} \%$ ) when incorporated in PMMA through a precursor via emulsion polymerization[11]. It was suggested that this performance might be due to the ability of $\mathrm{Ce}$ (III) to act as a reductant at elevated temperatures. Because it is not convenient to add FR fillers homogeneously through emulsion polymerization and with an intention to study potential synergy with MMT, a melt blending process was employed for the mixing of PMMA and $\mathrm{CeO}_{2}$ in combination with MMT. No nanodispersion of the cerium oxide was observed, while that is observed in emulsion polymerization. Thus, with micro-dispersion of $\mathrm{CeO}_{2}, \mathrm{MMT}$ is dominant in fire retardancy when evaluated by cone calorimetry [22]. Hence, there is no synergy between micro-dispersed $\mathrm{CeO}_{2}$ and MMT. Even when $\mathrm{CeO}_{2}$ is nano-dispersed, the combination with MMT is ineffective; this is likely due to the clay layers blocking the transport of $\mathrm{Ce}$ (III) particles to the surface.

\section{Layer by layer technique (LbL)}

LbL technique was first developed by Decher et al [17]. Since this is a relatively simple technique to fabricate multifunctional thin films that are typically less than one micrometer thick, it has aroused wide interest worldwide during the past decade $[1 ; 6 ; 45]$. The advantage of $L b L$ in fire performance of the materials with which it is coated is that it makes full use of the barrier properties of clay at the top surface. For other well dispersed nano-composites, either intercalated or exfoliated, the rising bubbles of decomposition products of polymers during burning push the clay layers to the top surface. Due to some factors, such as viscosity, clay loading etc., it is not easy to form a homogeneous char; cracks are usually seen after burning. Since MMT layers are negatively charged, it is possible to combine a positively charged substance to employ $\mathrm{LbL}$ technique for FR purpose. Grunlan's group did some interesting work in this area with the LbL technique [38-40]. They first employed this technique with an assembly of branched polyethylenimine (BPEI) and Laponite clay. Laponite clay is a synthetic clay whose aspect ratio is lower than MMT. By adjusting the $\mathrm{pH}$ values, the LbL film coated fabric samples exhibit moderately enhanced FR behavior compared to the control fabric by the vertical flame test. Since the aspect ratio of MMT is larger than Laponite and is more cost effective, in subsequent work, they investigated cotton fabric coated with BPEI and MMT clay, prepared via LbL. In this study, they tried two different $\mathrm{pH}$ values (7 and 10) and two clay suspensions $(0.2 \mathrm{wt} \%$ and $1 \mathrm{wt} \%)$. During actual burning in the vertical flame test, compared with control samples, afterglow time of cotton fabric coated with LbL technique was significantly reduced. The woven structure of the fabric, as observed in SEM images, is well preserved relative to the chars from coated fabrics, whereas the few ashes from the control fabric showed little structure. To obtain more details for FR behavior, they carried out microscale combustion calorimeter (MCC). The results indicate there is no evidence that more bi-layers (bL) (20 bLs) bring more heat release capacity (HRC) reductions than less bL coatings (5 bLs). However, the samples prepared at $\mathrm{pH}=10$ and $1 \mathrm{wt} \%$ MMT with 5bLs coating shows lowest 
HRC and total heat release (THR). This paper did not give an explanation on the FR mechanism of this system, thus, further studies are needed to interpret the above phenomena. Following the same procedure, another study from their group investigated an environmentally benign LbL coating composed of positively charged chitosan and anionic MMT. In this work, they also tried two different $\mathrm{pH}$ values ( 3 and 6 ) with 1 wt $\%$ MMT suspension. The $10 \mathrm{bL}$ coated PU prepared at $\mathrm{pH}=6$ exhibits a $52 \%$ PHRR reduction compared with control PU through cone calorimetry. While the samples prepared at $\mathrm{pH}=3$ only bring about less than $40 \%$ PHRR reduction. The first result is equivalent to $5 \%$ clay loading in PU matrix if conventional polymer nanocomposites are employed. But in their cone data, no TTI and smoke value are provided. From this work, it can be seen that $\mathrm{pH}$ value of the solution is an important factor which affects the final FR results. It seems that the LbL technique is a sound and practical method to achieve FR. However, can one scratch the LbL coatings off and thus expose the underlying fabric, in which case burning is assured? This, and similar questions on the durability of these coatings, must be addressed.

\section{Conclusion and prospects}

During the past several years, research on FR polymer-MMT based materials is still a hot area worldwide. The dispersion of MMT clay in polymer matrices is a major concern in FR behavior, as without good dispersion, there is no FR enhancement. There have been numerous updates in combination of various FR fillers such as CNT, LDH and IFR etc. For the future, we expect to see the increased use of combinations with the green FR materials, i.e. halogen-free materials. Another factor that must be considered is the ease of fabrication. As can be seen in this review, there have been some attempts to explore novel surfactants to modify MMT, however, some involve a complicated synthetic route, and sometimes, with low yields. As this review was being considered, the Nobel Prize in Chemistry for 2013 was awarded "for the development of multi-scale models for complex chemical systems". This award may indicate a trend in chemical and materials science research in future. As described in this paper, fire retardancy of
polymer-MMT nanocomposites, when in junction with other FR components, are sometimes very complicated. The trial and error method, which is the current situation, is expensive both in time and in money and this must be improved. The expense may be reduced substantially if new FR formulations are initiated by first by computer modeling. Thus, the requirements for FR researchers in future may include not only synthesis, fabrication, processing and evaluation of polymeric materials, but also proficiency with computer modeling. FR researchers must also broaden their view to find some effective means from related areas to better enhance FR performance of polymer composites. There is an old saying in China that "there are other hills whose stones are good for working jade". Hopefully, there will come up some "jades" in FR area to make our life safe and green.

\section{ABBREVIATIONS}

$\begin{array}{ll}\text { AFM } & \text { - Atomic Force Microscope } \\ \text { APP } & \text { - Ammonium Polyphosphate } \\ \text { ATH } & \text { - Alumina Trihydrate } \\ \text { BPEI } & \text { - Branched Polyethylenimine } \\ \text { CA } & \text { - Carbonization Agent } \\ \text { CNT } & \text { - Carbon Nanotubes } \\ \text { EPDM } & \text { - Ethylene-Propylene-Diene Terpolymer } \\ \text { EVA } & \text { - Ethylene-Vinyl-Acetate Copolymer } \\ \text { FR } & \text { - Fire Ketardant } \\ \text { HDPE } & \text { - High Density Polyethylene } \\ \text { HIPS } & \text { - High Impact Polystyrene } \\ \text { HRC } & \text { - Heat Release Capacity } \\ \text { IFR } & \text { - Intumescent Fire Retardant } \\ \text { LBL } & \text { - Layer-by-Layer Technique } \\ \text { LDH } & \text { - Layered Double Hydroxide } \\ \text { LDPE } & \text { - Low Density Polyethylene } \\ \text { LOI } & \text { - Limiting Oxygen Index } \\ \text { MCC } & \text { - Microscale Combustion Calorimeter } \\ \text { MH } & \text { - Magnesium Hydroxide } \\ \text { MMT } & \text { - Montmorillonite } \\ \text { PA6 } & \text { - Polyamide 6 } \\ \text { PER } & \text { - Pentaerythritol } \\ \text { PHRR } & \text { - Peak Heat Release Rate } \\ \text { PMMA - Poly (Methyl Methacrylate) } & \text { SAN } \text { - Poly (Acrylonitrile-co-Styrene) } \\ \text { SAXS } & \text { - Small-Angle X-ray Scattering } \\ \text { SEM } & \text { - Scanning Electron Microscope } \\ \text { TEM } & \text { - Transmission Electron Microscopy } \\ \text { THR } & \text { - Total Heat Release } \\ \text { TTI } & \text { - Time to Ignition } \\ \text { XRD } & \text { - X-ray Diffraction } \\ \text { ZrP } & \text { - Zirconium Phosphate } \\ & \end{array}$




\section{REFERENCES}

1. Ariga K., Hill J.P., Ji Q. Layer-by-layer Assembly as a Versatile Bottom-Up Nanofabrication Technique for Exploratory Research and Realistic Application. Phys. Chem. Phys., 2007, vol. 9, pp. 2319-2340.

2. Bakhracheva Yu.S. Fracture Toughness Prediction by Means of Indentation Test. International Journal for Computational Civil and Structural Engineering, 2013, vol. 9, no. 3, pp. 21-24.

3. Baron A.A, Bakhracheva Yu.S. A Method for Impact Strength Estimation. Mechanika, 2007, vol. 66, no. 4, pp. 31-35.

4. Baron A.A., Bakhracheva Yu.S., Osipenko A. Fracture Toughness Estimation by Means of Indentation Test. Mechanika, 2007, vol. 67, no. 5, pp. 33-36.

5. Baron A.A., Gevlich D.S., Bakhracheva Yu.S. Specific Plastic Strain Energy as a Measure of the Cracking Resistance of Structural Materials. Russian metallurgy (Metally), 2002, no. 6, pp. 587-592.

6. Bertrand P., Jonas A., Laschewsky A., Legras R. Ultrathin Polymer Coatings by Complexation of Polyelectrolytes at Interfaces: Suitable Materials, Structure and Properties. Macromol. Rapid Commun., 2000, vol. 21, pp. 319-348.

7. Beyer G. Flame Retardant Properties of EVANanocomposites and Improvements by Combination of Nanofillers With Aluminum Trihydrate. Fire and Materials, 2001, vol. 25, pp. 193-197.

8. Beyer G. Short Communication: Carbon Nanotubes as Flame Retardants for Polymers. Fire Mater., 2002, vol. 26, pp. 291-293.

9. Cai G.P., Dasari A., Yu Z.Z., Du X.S., Dai S.C., Mai Y.W., Wang J.Y. Fire Response of Polyamide 6 with Layered and Fibrillar Nanofillers. Polym. Degrad Stab., 2010, vol. 95 (5), pp. 845-851.

10. Cai G.P., Lu H.D., Zhou Y, Hao J.W., Wilkie C.A. Fire Retardancy of Emulsion Polymerized PMMA/ Cerium (IV) Dioxide and PS / Cerium (IV) Dioxide Nanocomposites. Thermochimica Acta, 2012, vol. 549, pp. 124-131.

11. Cai Y., Hu Y., Song L., Xuan S., Zhang Y., Chen Z., Fan W. Catalyzing Carbonization Function of Ferric Chloride Based on Acrylonitrile-ButadieneStyrene Copolymer/Organophilic Montmorillonite Nanocomposites. Polym. Degrad. Stab., 2007, vol. 92, pp. 490-496.

12. Carvalho H.W.P., Santilli C.V., Briois V., Pulcinelli S.H. Polymer-Clay Nanocomposites Thermal Stability: Experimental Evidence of the Radical Trapping Effect. RSC Advances, 2013, vol. 3, pp. 22830-22833.

13. Chen K., Wilkie C.A., Vyazovkin S. Revealing Nano-Confinement in Degradation and Relaxation Studies of Two Structurally Different Polystyrene-Clay Systems. J. Phys. Chem. B., 2007, vol. 111, pp. 12685-12692.
14. Chevrier J., Harley K.G., Bradman A., Gharbi M., Sjödin A, Eskenazi B. Polybrominated Diphenyl Ether (PBDE) Flame Retardants and Thyroid Hormone During Pregnancy. Environ. Health Perspect., 2010 , vol. 118, pp. 1444-1449.

15. Costache M.C., Jiang D.D., Wilkie C.A. Thermal Degradation of Ethylene-Vinyl Acetate Copolymer Nanocomposites. Polymer, 2005, vol. 46, pp. 6947-6958.

16. Costache M.C., Wang D.Y., Heidecker M.J., Manias E., Wilkie C.A. The Thermal Degradation of Poly(Methyl Methacrylate) Nanocomposites with Montmorillonite, Layered Double Hydroxides and Carbon Nanotubes. Polymers Adv. Tech., 2006, 17, pp. 272-280.

17. Decher G., Hong J.D. Method for Constructing Functional Living Materials, Resulting Materials and Uses Thereof. European Patent, Application Number 91113 464.1. Publication date: 2009-09-24. 12 p.

18. DiGangi J., Blum A., Bergman E., de Wit C.A., Lucas D., Mortimer D., Schecter A., Scheringer M. Shaw S.D., Webster T.F. San Antonio Statement on Brominated and Chlorinated Flame Retardants. Environ. Health. Perspect., 2010, vol. 118, A516-A518.

19. Gilman J., Kashiwagi T., Lichtenhan J. Nanocomposites: a Revolutionary New Flame Retardant Approach. SAMPE Journal, 1997, vol. 33, pp. 40-46.

20. Gilman J.W., Jackson C.L., Morgan A.B., Harris R., Manias E., Giannelis E.P., et al. Flammability Properties of Polymer-Layered-Silicate Nanocomposites. Polypropylene and Polystyrene Nanocomposites. Chem. Mater, 2000, vol. 12, pp. 1866-873.

21. Gilman J.W., Kashiwagi T. Polymer-Clay Nanocomposites. New York, 2000, pp. 193-206.

22. Guipeng Cai, Charles A. Wilkie, Shaorong $\mathrm{Xu}$, Zhengzhou Wang. Further Studies on Polystyrene/ Cerium (IV) Oxide System: Melt Blending and Interaction With Montmorillonite. Polym. Adv. Technol., 2014, vol. 25, pp. 217-222.

23. Herbstman J.B., Sjödin A., Kurzon M., Lederman S.A., Jones R.S., Rauh V., Needham L.L., Tang D. Niedzwiecki M., Wang R.Y., Perera F. Prenatal Exposure to PBDEs and Neurodevelopment. Environ. Health Perspect., 2010, vol. 118, pp. 712-719.

24. Huang G.B., Gao J.R., Li Y.J., Han L., Wang $X$. Functionalizing Nano-Montmorillonites by Modified with Intumescent Flame Retardant: Preparation and Application in Polyurethane. Polym. Degrad. Stab., 2010, vol. 95, pp. 245-253.

25. Huang G.B., Li Y.J., Han L.A., Gao J.R., Wang X. A Novel Intumescent Flame RetardantFunctionalized Montmorillonite: Preparation, Characterization, and Flammability Properties. Appl. Clay Sci., 2011, vol. 51, pp. 360-365. 


\section{ТЕХНИКО-ТЕХНОЛОГИЧЕСКИЕ ИННОВАЦИИ}

26. Jang B.N., Costache M.C., Wilkie C.A. The Relationship Between Thermal Degradation Behavior of Polymer and the Fire Retardancy of Polymer/Clay Nanocomposites. Polymer, 2005, vol. 46, pp. 1067810687.

27. Jang B.N., Wilkie C.A. The Effect of Clay on the Thermal Degradation of Polyamide 6 in Polyamide 6/Clay Nanocomposites. Polymer, 2005, vol. 46, pp. 3264-3274.

28. Jang B.N., Wilkie C.A. The Effects of Clay on the Thermal Degradation Behavior of Poly (styreneco-acrylonitirile). Polymer, 2005, vol. 46, pp. 9702-9713.

29. Jang B.N., Wilkie C.A. The Thermal Degradation of Polystyrene Nanocomposites. Polymer, 2005, vol. 46, pp. 2933-2942.

30. Kashiwagi T., Danyus R., Liu M., Zammarano M., Shields J.R., Enhancement of Char Formation of Polymer Nanocomposites Using a Catalyst. Polymer Degradation and Stability, 2009, vol. 94, pp. 2028-2035.

31. Kashiwagi T., Grulke E., Hilding J., Groth K., Harris R., Butler K., Shields J., Kharchenko S., Douglas J. Thermal and Flammability Properties of Polypropylene/carbon Nanotube Nanocomposites. Polymer, 2004, vol. 45, pp. 4227-4239.

32. Kiliaris P., Papaspyrides C.D. Polymer/ Layered Silicate (Clay) Nanocomposites: An Overview of Flame Retardancy. Progress in Polymer Science, 2010, vol. 35, pp. 902-958.

33. Lai X.J., Zeng X.R., Li H.Q., Liao F., Yin C.Y., Zhang H.L. Synergistic Effect of PhosphorusContaining Montmorillonite with Intumescent Flame Retardant in Polypropylene. Journal of Macromolecular Science, Part B: Physics, 2012, vol. 51, pp. 1186-1198.

34. Laufer G., Carosio F., Martinez R., Camino J., Grunlan J.C. Growth and Fire Resistance of Colloidal Silica-Polyelectrolyte Thin Film Assemblies. J. Colloid Interface Sci., 2011, vol. 356, pp. 69-77.

35. Laufer G., Kirkland C., Cain A.A., Grunlan J.C. Clay-Chitosan Nanobrick Walls: Completely Renewable Gas Barrier and Flame-Retardant Nanocoatings. ACS Applied Materials \& Interfaces, 2012, vol. 4, pp. 1643-1649.

36. Lenza J., Merkel K., Rydarowski H. Comparison of the Effect of Montmorillonite, Magnesium Hydroxide and a Mixture of Both on the Flammability Properties and Mechanism of Char Formation of HDPE Composites. Polymer Degradation and Stability, 2012, vol. 97, pp. 2581-2593.

37. Levchik S.V., Weil E.D. A Review of Recent Progress in Phosphorus-Based Flame Retardants. J. Fire Sci., 2006, vol. 24, pp. 345-364.

38. Li Y.C., Mannen S., Morgan A.B., Chang S., Yang Y.H., Condon B., Grunlan J.C., Intumescent AllPolymer Multilayer Nanocoating Capable of
Extinguishing Flame on Fabric. Adv. Mater., 2011, vol. 23, pp. 3926-3931.

39. Li Y.C., Schulz J., Grunlan J.C. Polyelectrolyte/ Nanosilicate Thin-Film Assemblies: Influence of $\mathrm{pH}$ on Growth, Mechanical Behavior, and Flammability. ACS Applied Materials \& Interfaces, 2009, vol. 1 (10), pp. 2338-2347.

40. Li Y.C., Schulz J., Mannen S., Delhom C., Condon B., Chang S., Zammarano M., Grunlan J.C. Flame Retardant Behavior of Polyelectrolyte-Clay Thin Film Assemblies on Cotton Fabric. ACS Nano, 2010, vol. 4, pp. 3325-3337.

41. Meifang Liu, Xin Zhang, Mauro Zammarano, Jeffrey W. Gilman, Takashi Kashiwagi. Flame Retardancy of Poly(styrene-co-acrylonitrile) by the Synergistic Interaction Between Clay and Phosphomolybdate Hydrates. Polymer Degradation and Stability, 2011, vol. 96, pp. 1000-1008.

42. Morgan A.B. Flame Retarded PolymerLayered Silicate Nanocomposites: a Review of Commercial and Open Literature Systems. Polymers Adv. Tech., 2006, vol. 17, pp. 206-217.

43. Pack S., Kashiwagi T., Cao C.H., Korach C.S., Lewin M., Rafailovich M.H. Role of Surface Interactions in the Synergizing Polymer/Clay Flame Retardant Properties. Macromolecules, 2010, vol. 43, pp. 5338-5351.

44. Patra S.K., Prusty G., Swain S.K. UltrasoundAssisted Synthesis of PMMA/Clay Nanocomposites: Study of Oxygen Permeation and Flame Retardant Properties. Bull. Mater. Sci., 2012, vol. 35, pp. 27-32.

45. Podsiadlo P., Shim B.S., Kotov N.A. Polymer/ Clay and Polymer/Carbon Nanotube Hybrid OrganicInorganic Multilayered Composites Made by Sequential Layering of Nanometer Scale Films. Coord. Chem. Rev., 2009, vol. 253, pp. 2835-2851.

46. Ray S.S., Okamoto M. Polymer-Layered Silicate Nanocomposites: a Review From Preparation to Processing. Progress in Polymer Science, 2003, vol. 28, pp. 1539-1641.

47. Ribeiro S.P.S., Estevao L.R.M., Nascimento R.S.V. Effect of Clays on the Fire-Retardant Properties of a Polyethylenic Copolymer Containing Intumescent Formulation. Sci. Technol. Adv. Mater, 2008, vol. 9.7 p.

48. Schartel B., Potschke P., Knoll U., AbdelGoad M. Fire Behaviour of Polyamide 6/multiwall Carbon Nanotube Nanocomposites. Eur Polymer J., 2005, vol. 41, pp. 1061-1070.

49. Semenova L.M., Bakhracheva Yu.S., Semenov S.V. Laws of Formation of Diffusion Layers and Solution of the Diffusion Problem in TemperatureCycle Carbonitriding of Steel. Metal Science and Heat Treatment, 2013, vol. 55, no. 1-2, pp. 34-37.

50. Shapochkin V.I., Semenova L.M., Bakhracheva Yu.S., Gyulikhandanov E.L., Semenov S.V. Effect of Nitrogen Content on the Structure and 
Properties of Nitrocarburized Steel. Metal Science and Heat Treatment, 2011, vol. 52, no. 9-10, pp. 413-419.

51. Shen Z.Q., Chen L., Lin L., Deng C.L., Zhao J. and Wang Y.Z. Synergistic Effect of layered nanofillers in intumescent flame- retardant EPDM: montmorillonite versus layered double hydroxides. Ind. Eng. Chem. Res., 2013, vol. 52, pp. 8454-8463.

52. Shi Y., Kashiwagi T., Walters R.N., Gilman J.W., Lyon R.E., Sogah D.Y. Ethylene vinyl acetate/layered silicate nanocomposites prepared by a surfactant-free method: enhanced flame retardant and mechanical properties. Polymer, 2009, vol. 50, pp. 3478-3487.

53. Suihkonen R., Nevalainen K., Orell O., Honkanen M., Tang L.C., Zhang H., Zhang Z., Vuorinen J. Performance of Epoxy Filled With Nanoand Micro-Sized Magnesium Hydroxide. J. Mater. Sci., 2012, vol. 47, pp. 1480-1488

54. Swain S.K., Isayev A.I. Effect of Ultrasound on HDPE/Clay Nanocomposites: Rheology, Structure and Properties. Polymer, 2007, vol. 48, pp. 281-289.
55. Takashi Kashiwagi, Fangming Du, Jack F. Douglas, Karen I. Winey, Richard H. Harris Jr., John R. Shields, Nanoparticle Networks Reduce the Flammability of Polymer Nanocomposites. Nature Materials, 2005, vol. 4, pp. 928-933.

56. Wang L., Xie X., Su S., Feng J., Wilkie C.A. A Comparison of the Fire Retardancy of Poly (Methyl Methacrylate) Using Montmorillonite-Layered Double Hydroxide and Kaolinite. Polymer Degradation and Stability, 2010, vol. 95, pp. 572-578.

57. Wang W.S., Liang C.K., Chen Y.C., Su Y.L., Tsai T.Y., Chen-Yang Y.W. Transparent and Flame Retardant PMMA/Clay Nanocomposites Prepared with Dual Modified Organoclay. Polym Adv Technol, 2012, vol. 23, pp. 625-631.

58. Zhu J., Morgan A.B., Lamelas F.J., Wilkie C.A. Fire Properties of Polystyrene-Clay Nanocomposites. Chem. Mater, 2001, vol. 13, pp. 3774-3780.

59. Zhu J., Uhl F., Morgan A.B., Wilkie C.A. Studies on the Mechanism by Which the Formation of Nanocomposites enhances Thermal Stability. Chem. Mater., 2001, vol. 13, pp. 4649-4654.

\section{ПОСЛЕДНИЕ ДОСТИЖЕНИЯ \\ В ОБЛАСТИ ОГНЕЗАЩИТНЫХ КОМПОЗИТОВ С ПОЛИМЕРНЫМИ МАТРИЦАМИ}

\section{Цаи Гуипенг}

Доктор наук, профессор кафедры химии и огнезащитных материалов научно-исследовательского центра, Университет Маркетта charles.wilkie@marquette.edu Висконсин Авеню, 1250, г. Милуоки, Штат Висконсин 53233, США

\section{Уилки Чарльз А.}

Доктор наук, профессор кафедры химии и огнезащитных материалов научно-исследовательского центра, Университет Маркетта charles.wilkie@marquette.edu Висконсин Авеню, 1250, г. Милуоки, Штат Висконсин 53233, США

Аннотация. В данной работе исследуются современные огнестойкие материалы на основе органически-модифицированного наноструктурированного монтмориллонита. Проанализировано несколько основных возможностей создания таких материалов с точки зрения экологической и экономической эффективности.

Ключевые слова: огнестойкость, огнеупорные глины, нанокомпозиты, полимерная матрица, экологические проблемы. 